\title{
Family Communication about Money: Why the Taboo?
}

\author{
Dr. Liezel Alsemgeest \\ Centre for Financial Planning Law, University of the Free State, South Africa \\ Email: alsemgeestl@ufs.ac.za
}

\section{Doi:10.5901/mjss.2014.v5n16p516}

\begin{abstract}
Money is seen as such of a taboo subject that even parents are uncomfortable talking to their children about it. Society regard money as both profane and sacred, while social and cultural meanings and associations are attached to money. Also, money presents psychological factors such as feelings of power, shame and guilt. All of these reasons cause individuals to regard money as a taboo subject and avoid communication about it, even in the family context. If parents do not talk to children about money, then children could inherit their parent's perceived attitudes, behaviours and actions with regard to money (good and bad). The contribution of this article is that it discusses money as a taboo subject, but also brings it into the realm of the family in an effort to indicate the importance of financial communication as it affects financial attitudes and behaviours later in life. Responsible communication about money is suggested, whereby the children are not necessarily burdened with sensitive financial information, but rather openness and honesty about money, so that mistakes, negative emotions and anxieties about personal finances are not conferred upon the children from the parents.
\end{abstract}

Keywords: Family communication, money, taboo, psychological

\section{Introduction}

"The money taboo is a serious psychological problem because, though we do not talk freely about money, it is of major concern to almost everybody... This taboo keeps people from finding money's proper place in their lives." (Trachtman 1999:280).

In many Western societies, sensitive issues such as sex and death are discussed more openly than in the past. However, money is still a taboo subject and is perceived to be an impolite conversation topic (Furnham and Argyle 1998). Consequently, children might grow up in households where their parents never talk to them about money. These children often do not know their parents' financial situation, how much they earn and how much they save. When these children become adults, they have never gained knowledge on basic financial management and in certain cases they inherit irrational beliefs, attitudes and anxieties towards money (Atwood 2012). During a 2008 poll in the United States, approximately $94 \%$ of parents admitted that, despite feeling extremely uncomfortable talking about money, they are their children's primary information source when it comes to financial management (Romo 2011). Teaching children financial management skills is mainly left to parents, but many parents do not have the necessary skills to financially educate their children, these skills are not discussed at home and some parents feel that it is not their duty to teach their children about money. Although it seems as if parents do not want to do the teaching, they are the people children want to turn to with regard to money (Jorgensen and Savla 2010).

Since the 1980s the majority of industrial countries have shown an accelerated increase in consumer spending, debt usage has sky-rocketed and saving rates have declined to severely low levels (Betti, Dourmashkin, Rossi and Yin 2007). Even though money plays such a significant role in the everyday life of every individual and in several countries consumers are in dire straits; we are still not talking freely about it, because of how it affects us psychologically and culturally.

Money is perceived as a private matter that has a strong link with self-esteem. Money has been described as both sacred and profane according to its sources and uses (Belk and Wallendorf 1990). Money consumes vast amounts of psychological and emotional energy, because we think, argue and dream about it. Money is an inert thing; however, we give it subjective and affective meanings. Everyone casts their own definition onto money, as well as having rules and regulations and social norms pertaining to it. It has been said that money is one of the most emotionally charged objects on earth, only food and sex can be close competitors in how strongly individuals perceive it in terms of feelings, meaningfulness and significance (Mitchell and Mickel 1999). 
Acknowledgement of the role that money plays in our lives might assist us to start breaking down the barriers of this taboo and start talking more freely about personal finances. The objective of this article is to give a theoretical overview of the formation and transmission of money-related attitudes and behaviour within the family to determine why communication about money in the family context is so difficult. The article will start off by providing an overview of family communication about money. This will be followed by literature related to family communication about money, money as a taboo subject, the social and cultural impact, as well as the psychological impact of money, with specific reference to power and feelings of shame and guilt. These topics will be presented to answer the question of why communication about money is so difficult to have, even in the family context. The article concludes with some suggestions on how to make money a more open and acceptable conversation subject in the family in order to increase financial well-being of all family members.

\section{Family Communication about Money}

There is a widely held belief that family plays a significant role in consumer socialisation, however, there is an absence of research on the skills, values, attitudes and behaviours that youngsters develop from their parents and the role family communication plays in the process of acquisition (Moschis 1985). Specifically, very little research has been done on how parents communicate with their children about money. Romo (2011) reports that $39 \%$ of parents in the United States will rather talk to their children about drugs and alcohol, while $27 \%$ will feel more comfortable talking about sex and dating than money, $11 \%$ of parents indicated that they would never reveal the family's income to their children and $14 \%$ of parents would never disclose family debt. Ironically, despite being their children's primary source of information on financial management, parents do not want to talk to their children about money. Children are often confronted with the same money issues and/or problems than their parents. Communication about these financial issues can either affect the children positively or negatively. As financial issues are seen as a taboo and very private matter, the Communication Privacy Management Theory (Petronio 2002) can be applied to it.

This theory is based on three hypotheses. The first is that individuals are unsure about whether to disclose personal information or not. The second is that individuals create their own boundaries to control the movement of private information. These boundaries help an individual to establish whom the information will be shared with, as well as to what degree sharing will take place. As soon as private information is shared with someone else, this person then becomes a co-owner of the information and is included within the boundaries set, irrespective of the person's age, maturity level of the individual or how receptive the individual is. A child might not be mature enough to handle certain sensitive information. The third hypothesis is that people construct their own rules on how open or closed these boundaries will be and how much they will reveal or conceal of their personal information. A risk-benefit criterion can be applied to these boundaries. If an individual feels that there is more benefit than risk in revealing the information, then they would be more willing to reveal the personal information, but if they feel that the risk is more than the benefit, then they will feel too vulnerable and therefore conceal the information (Petronio 2002). If a parent is afraid to be judged by their child, they would rather conceal the information. Individuals who are ashamed, feel guilty or attach their self-esteem to their financial situation, would perceive the risk of revealing personal financial information as too risky and would therefore be reluctant to disclose information.

A parent's concern for his or her child's well-being would also come into play as suggested by Romo (2011). Parents do not want to burden their children with financial worries or make them feel shame and embarrassment about it. This is understandable, but is a complete lack of communication about finances the answer to this issue?

Adults remember certain messages related to money that they received during childhood from their parents. These messages are retained and can shape their view of money. Negative messages such as the following, could lead to harmful attitudes and anxieties (Matthews 1991):

- 'My mother said only poor people go to heaven.'

- 'My father said only criminals were wealthy.'

- 'My parents said I was a popular kid because they were rich enough to have a house with a tennis court. They told me, quite plainly, that if one was without money, one would be without friends.'

- 'My parents, who were quite well off, never let me spend a dime without me begging and pleading. They said that I must never forget that we could 'wake up poor in the morning'. Sometimes I would lie awake at bedtime, afraid to close my eyes for fear I would wake up hungry and cold.'

These negative messages, whether verbally or not, are bequeathed from generation to generation. Our adult behaviour, when it comes to money can also be linked to self-esteem, to validate an external self-image or because there 
was a lack of money during childhood (Atwood 2012).

It is necessary to include children more in economic activity, because the modern consumer is inundated with complex and demanding economic information, markets and products. There is no agreed method of teaching children about money; however, a consensus exists that children should be taught, and that the first port of call should be the parents (Furnham and Argyle 1998). According to Romo (2011) parents that do disclose financial information to children do it on a need-to-know basis, which on the one hand protects the child from undue worrying and embarrassment, but does not overprotect the child in preparation for the real world. Also, disclosing the necessary financial information fosters trust between the child and the parent. There is a fine line between protecting children, while also providing them with enough financial information to prepare them, and simultaneously encourage trust.

\section{Money as a Taboo Subject}

The word taboo is defined in the Oxford English Dictionary (2013) as 'a social or religious custom prohibiting or restricting a particular practice or forbidding association with a particular person, place or thing; prohibited or restricted by social custom'. The original meaning of the Tongan word tabu literally means 'forbidden' (Allan and Burridge 2006). According to Trachtman (1999), people feel embarrassed and conflicted about money discussions and would rather avoid the subject altogether, due to the emotional taboo on personal aspects of this subject. Scores of individuals admit that they are largely ignorant about the economy and money, although in many cases these individuals would also have strong opinions on certain economic factors such as taxation and government spending (Furnham and Argyle 1998). However, when it comes to personal financial issues, such as our incomes, indebtedness, or how we feel and think about money, the subject is largely neglected (Trachtman 1999), also in the family context.

Money can be defined in economic terms as a medium of exchange (Dyer 1989), a unit of account (Sardoni 2008), a store of value (Abdullah 2013) or a standard of deferred payment (McKinnon 2001), in other words, it has a quantitative meaning, it is profane, ordinary and mundane. However, money has a much more sacred meaning that is both qualitative and emotional. Society provides a meaning to money in which it is revered, feared, worshipped and treated with the highest respect through gifts, collectibles and heirlooms (Belk and Wallendorf 1990).

In direct contrast to the sacred meaning of money, it is also regarded as a profane commodity. Freud even compared money to symbolic faeces, related to feelings of embarrassment about it (Barth 2001). In this case money is provided with the lowliest status and seen as evil that provokes feelings of revulsion and disgust. Freud's relative primitive interpretation of money is basically linked with the 'most repugnant of all things, will be bound to become an object of at least subconscious aversion and repression', a real taboo (Herbert 2002). A profane commodity is something that easily can be exchanged for something else equivalent in value. A profane commodity is not revered by associating it with loved ones or other people or being part of a collection (Appadurai 1986). These two interpretations of money therefore provides for inner conflict as money is seen as both sacred and good (the almighty dollar), as well as evil and destructive (the filthy lucre) (Belk and Wallendorf 1990).

Money has been associated with concepts such as power, sex, love and narcissism, while we operate in a capitalist world that pretends it is a classless meritocracy where everyone is equal. All of these aspects cause conflict which instil in people to either keep quiet about money or deal with it in an euphemistic manner (Trachtman 1999). Money has a social and cultural impact on us that dictates what other people think of us, as well as a psychological impact that influence what we think of ourselves.

\section{Social and Cultural Impact of Money}

Each society and social group has its own culture. The culture includes issues such as beliefs, values, rules of interaction (Ng'and'a and Nyongesa 2012) and unofficial taboo subjects. If there is an unspoken agreement between group members to avoid a specific taboo, it is logical that this is part of the group's culture and that it is respected by group members (Shulman 2008). From a psychological viewpoint, money has different meanings. Clinical psychologists (Klontz, Bivens, Klontz, Wada and Kahler 2008) report that money relates to states of anxiety and neuroses, while developmental psychologists (Weisgram, Bigler and Liben 2010) are interested in how meanings of money develop from childhood into adulthood. There is a definitive link between how money affects personality matters such as self-esteem and identity, while industrial psychologists (Rynes, Gerhart and Minette 2004) deal with money as a valued outcome of employment. According to sociologists, money can be culturally defined in a social context (Goodwin 2008). All of these viewpoints indicate that money has three commonalities namely that it is affective, symbolic and has behavioural components (Mitchell and Mickel 1999). According to Shepherd and Stephens (2010) culture is the interaction between mental 
processes and the external environment. Our culture trains us to interact with our social environment. People can both design their social world, as well as be shaped by this world.

Powerful and complex associations are formed around money, which would impact on how people ultimately use it. There are monetary beliefs and values that are ingrained in some people's psyche such as that rich people are bad or that you can only become wealthy if you work hard and look after the pennies and the pounds will look after themselves (Furnham and Argyle 1998). Even the Bible states that the love of money is the root of all evil (1 Timothy 6:10). The love of money is one of the biggest motivations for human beings, not just for what it can buy, but it is also desired in and for itself. Money can be described as a 'screen onto which any psychological issues can be projected and a magnet which attracts all sorts of emotional concerns' (Trachtman 1999:275).

Humans are cultural and social animals where dependence on each other is necessary to get what they need and want. Humans are socially interdependent and have a strong need to belong and be accepted. Money provides a means of gaining acceptance even if a person is not liked by the group. Social popularity is therefore not needed when money can act as a substitute. In the social system either money or social inclusion is necessary in order to form part of a group (Zhou, Vohs and Baumeister 2009). Money can be used as a measure of how society perceives us, as we have a level of control on what we present to the world (houses, cars, clothing and jewellery). We provide society with non-verbal cues of our status (Georgarakos, Halassos and Pasini 2013).

Attitudes, behaviours, beliefs and anxieties about money are often inherited from the way people were brought up and this spill over into relationships with others. In many cases money is not even often discussed with those closest to us. According to Atwood (2012) couples would rather talk about sex and infidelities than about the management of their personal finances or how much they earn, treating money as the last taboo. According to research done by Romo (2011), parents do not disclose financial information to their children because of two main reasons, namely that financial issues should not be a child's concern and that money is a taboo subject. According to the parents, children should not worry about the family's finances, children should not feel shame with regard to the family's finances and children should not be made to judge their parents. They consider it inappropriate to talk about finances. These parents perceive talking about money as a cultural taboo, as the majority of the parents grew up in households where money was not discussed. These parents' lack of personal financial disclosure often stems from long-term privacy values and the belief that not talking openly about money is completely normal. Evidently, parents do want to protect their children from worrying and embarrassment, but they also want to protect themselves from feeling judged. However, overprotecting children from money issues, could lead to ignorance that might jeopardise the family's financial well-being.

\section{Psychological Impact of Money}

Money is an important aspect of every individual's life. It is essential in fulfilling basic needs such as food and shelter, however money is also used by individuals in order to maintain and shape self-esteem. Thus, money provides for needs near the base of Maslow's hierarchy (1943), but money can also lead to a sense of self-worth, which could bring about self-actualisation. Money can be spent to further different ends or reach potential (Goodwin 2008). Self-esteem is needed in order to function optimally in the human motivation hierarchy and is in no small part obtained by feelings of above average intelligence, morality, generosity and competence. A feeling of competence is sometimes obtained from an individual's ability to earn money. A positive self-image is in some cases obtained through higher earnings of money. Therefore, money and self-esteem offset each other, as both leads to feelings of satisfaction (Zhang 2009). Money can incite both positive (power) and negative feelings (shame and guilt) that can either build or break-down self-esteem.

\subsection{Power}

Money confers social power and therefore it can be seen as a measure of worthiness. The more powerful will have higher remuneration or visa versa. And this power will create a better image, as well as social structure for the individual (Furnham and Argyle 1998). In some cases money is also linked to happiness, because of the belief that the wealthier you are, the happier you will be. This notion is augmented by the materialistic society in which we operate (Chaplin and John 2010). Money can be seen as both a tool and a drug. A tool in the sense that it is a means to an end, but it also acts as a metaphorical drug. The definition provided by Belk and Wallendorf (1990) with regard to money as both sacred and profane can be linked to money as a tool and a drug. The profane everyday quantitative definition of money as a means of exchange has a connection with Lea and Webley's tool theory, while money as something sacred, that has meaning can be linked with the drug theory, as individuals can act in puzzling ways when it comes to money (Lea and Webley 2006). Even though money is not a biological drug - it can act as a stimulus that "has motivational properties because it 
produces the same neural, behavioural, or psychological effect as some other stimulus that is biologically significant. A drug in this extended sense is any functionless motivator, obtaining its motivational effect by a parasitic action on a functional, evolutionarily adaptive system'. Drug theory is therefore the exact opposite as tool theory, because with the latter, an individual's only interest in money is in the possible biological rewards that can be obtained at a later time, through exchange; for instance trading money for food. According to drug theory money, in itself, in some cases can provide the illusion of instant fulfilment, giving it power from both a tool standpoint, as well as a drug standpoint. Gambling as an addiction is a well-researched field and provides the same non-biological motivational properties (Blaszczynski and Nower 2010). Being overly obsessed with money is also called money-worshipping disorder and includes overspending, compulsive buying, unreasonable risk-taking with money and pathological gambling. These money worshipping disorders are engrained in the belief that money answers all questions (Lowrance 2011). Simmel (2004) states that nothing else which has its value purely as a means and can be converted into something with a definite value, been able to influence our consciousness, quite like money. The absolute need for money leads to money not being a means, but rather an end in itself.

Money reflects power not only in society, but also in the family. If a husband earns more than the wife, then the wife would tend to do the majority of the household chores. However, when the wife earns more than the husband, there in some cases tend to be an equal share of household chores (Atwood 2012). In other cases this could lead to conflict as the traditional role of men as the providers in the household is challenged and it can defy theories of equality in marriage (Vogler 2005). There is the viewpoint that marriage should be based on the ideology that everything is shared, irrespective of earns what or how much. Conversely, there is also the belief that whatever an individual earns is his/hers and that they 'own' the money and they have the right to do with it what they please. The latter viewpoint conflicts directly with equal sharing and brings forth the idea that breadwinners within the family have a legitimate right to more power than their spouse or the rest of the household. Even though couples may claim that they share money equally, in practice it has been proven that earning money is seen as an implicit right to ownership and control over said money (Burgoyne 1990).

\subsection{Shame and Guilt}

An emotion of shame devalues an individual's perception of him-/herself. This negative emotion can make an individual feel small and insignificant in front of real or imaginary peers. Money is seen as a manifestation of one's ability and could be seen as a measure of power. There is a definitive link between the negative feeling of shame and the need for money, as money is then seen as a means to increase an individual's self-esteem and gaining the respect of others, in an effort to increase feelings of self-worth. It has also been found that poverty enhances individual's feelings of shame and that these negative feeling could actually lead to a continuous cycle of poverty and greed (Wang, Cheng, Chiou and Kung 2012). Shame is not limited to the poor, as with wealthy individuals' beliefs such as the following can also cause shame and exacerbate the money taboo issue (Trachtman 1999):

- It is in bad taste to talk about money

- People will be able to manipulate me if they know about my money

- Our children should not know how much we have, because then they will not amount to anything by themselves

- I feel embarrassed or ashamed, because I do not deserve to be better off than others

- I fear that people will judge me for my money and not for who I really am.

According to research done by Trachtman (1999) individuals gave a variety of reasons why they do not talk about money. Some say that talking to others about money, would immediately cause a social distance, while someone else mentioned that while she is wealthy now, she grew up very poor and when talking about money she feels some form of "survivors guilt". Debt is another subject that contributes to feelings of shame and guilt. Individuals would rather tell others about their income than revealing how much they owe (Georgarakos et al. 2013). Individuals seem to feel shame when they think others are judging them or labelling them, either for being poor or rich or indebted.

\section{Discussion and Suggestions}

Individuals are willing to voice their opinions about general financial issues such as government spending and taxes, but when it comes to the personal side of finances, many individuals remain silent. Personal money issues such as income, debt usage and savings are seen as a taboo subject and we are even keeping financial information from our families. The 
majority of Western economies are showing increased debt usage, while savings rates are so low that a great number of people will not be able to retire, but will be dependent on the government. Money mismanagement seems to be the norm, rather than the exception.

Money plays an important part in everyone's daily lives. We use money as a medium of exchange and a store of value; however, we also desire money not for what it can buy, but in and for itself. We symbolises money in the sense that it impacts on each individual in a social and cultural sense, but also on a psychological level. Because of money we can be part of a group, we can belong. Money in essence can buy acceptance. Acceptable attitudes, behaviours, beliefs and anxieties are determined by the culture within which an individual operates and financial attitudes, behaviours, beliefs and anxieties shape our lives. We, in a sense, inherit the messages that are instilled in us from a young age. The social and cultural impact of money defines what we think of ourselves, while the psychological impact of money defines what other people think of us. Money can give us a sense of power as we feel more secure in our own abilities and more able to reach our potential. Money can act as a non-biological drug and as motivator. However, money can also cause negative feelings such as shame for both poor and wealthy individuals, while elements such as excessive debt can cause guilt. Table 1 provides a summary of the reasons why money is a taboo subject, as well as the possible effects these beliefs, actions and connotations could have on the family and specifically on children.

Table 1: Possible reasons for money as a taboo subject and the possible impact thereof on the family

\begin{tabular}{|c|c|}
\hline Reason for the taboo & Possible effect on the family and children \\
\hline $\begin{array}{l}\text { It is customary (the norm) } \\
\text { not to talk about finances } \\
\text { (Trachtman 1999). }\end{array}$ & $\begin{array}{l}\text { Children learn from parents, as well as from the rest of society that speaking about finances is not } \\
\text { accepted, which could lead to continued neglect of the discussion of this subject as an important part of } \\
\text { everyday life. }\end{array}$ \\
\hline $\begin{array}{l}\text { Sacred and profane } \\
\text { meanings (Belk and } \\
\text { Wallendorf 1990) }\end{array}$ & $\begin{array}{l}\text { Money is seen as both something that should be feared, revered, worshipped, as well as something that is } \\
\text { mundane and revolting. These contrasting meanings could confuse individuals on the role that money } \\
\text { should play in their lives and they could assign either too much value or pay no heed to it. }\end{array}$ \\
\hline $\begin{array}{l}\text { Social and cultural } \\
\text { connotations attached to } \\
\text { money }\end{array}$ & $\begin{array}{l}\text { Parents tend to not talk to their children about money, even though they might be their children's primary } \\
\text { source of financial information (Romo 2011). This could lead to children inheriting their parents' perceived } \\
\text { attitudes and behaviours with regard to money, whether good or bad. Also, money seems to provide a } \\
\text { form of acceptance in a social context (Zhou et al. 2009) as the social group would judge the individual on } \\
\text { their social status and not necessarily personality or popularity. This could lead to the perception that } \\
\text { having money is the answer to gaining acceptance. }\end{array}$ \\
\hline $\begin{array}{l}\text { Feelings of power or } \\
\text { inferiority as } \\
\text { psychological factor } \\
\text { associated with money }\end{array}$ & $\begin{array}{l}\text { With virtually no communication about money and the role it should play in everyday life, children could } \\
\text { conclude that money gives power, happiness and fulfilment (Chaplin and John 2010). This power is not } \\
\text { only manifested in society, but could also become apparent in the household, as the individual that earns } \\
\text { the most money could also have a bigger say (Atwood 2012). The opposite could also be true, in that a } \\
\text { lack of money could reveal feelings of inferiority. This psychological impact of money impacts on } \\
\text { individuals' self-esteem, identity and could lead to feelings of anxiety and neurosis (Belk and Wallendorf } \\
\text { 1990). }\end{array}$ \\
\hline $\begin{array}{l}\text { Feelings of shame, } \\
\text { embarrassment and guilt } \\
\text { as psychological factors } \\
\text { associated with money }\end{array}$ & $\begin{array}{l}\text { One of the main reasons parents do not want to talk about money to their children is to shield them from } \\
\text { feelings of shame and embarrassment. If parents feel vulnerable about their financial situation, they would } \\
\text { not want their children to judge them, which is understandable (Romo 2011). However, this non-disclosure } \\
\text { could lead to children following in their parents' financial footsteps, if their only reference is that of their } \\
\text { parents' perceived financial attitudes, behaviours and action. Parents could rather, not necessarily } \\
\text { disclose sensitive information, but at least talk to children about financial choices. }\end{array}$ \\
\hline
\end{tabular}

This taboo in society often prevents families from talking openly to each other about money. In a sense, they want to protect their children, as well as themselves from vulnerability. Those parents that do talk to their children about money issues do so in order to prepare them for the real world, but on a need-to-know basis. They also believe that it fosters a trusting relationship. There is a definite place for financial openness in families. Talking to children about the need for savings and responsible money management, while still discussing issues such as debt and even problems experienced by parents (without causing undue worry) could help prepare children for what awaits them in the real world. Parents need to be very careful with what is discussed with children and especially what messages children are subjected to, because it can influence their attitudes and behaviours and there is a likelihood of passing it on to other generations. For instance, children should not be kept in the dark if money is tight; the parents should involve children in the family's economic decision-making to teach responsibility, but without causing distress, while always remaining optimistic that if everyone works together, the family will become financially healthy. In the long term this openness will foster trust. The 
focus here is on communication and not the education of children; as parents might not have the necessary financial literacy to educate their children on financial matters effectively. However, financial openness should increase children's' financial receptiveness and encourage learning.

Communicating to children about the cultural, social and psychological effect of money on the family is important. Parents need to be honest with themselves, as well as with their children on what role money plays in their lives to ensure family well-being. Children should know that money is not the answer to everything and that their worth is not dependent on having money or not. Mostly, these messages might be received non-verbally from parents, as parents' self-esteem and relationship to money will teach children much more than verbal cues about money. The essence is that breaking the barriers of this taboo should start in the family unit and that remains the responsibility of the parent. If it can become more socially acceptable to talk about money in the home, it will be more acceptable to talk about it to others. By openly discussing financial aspects, individuals might be more receptive and accessible to learn and become less socially, culturally and psychologically reliant on money and become financially healthy.

\section{Conclusion}

Money is seen as the last taboo subject in many Western cultures, as individuals would rather discuss sex, death and infidelities than discuss personal financial issues. Even though money is not discussed openly, it plays a major role in everyone's life since we not only appreciate it for what it can buy us, but we also give it meaningfulness and significance and are emotionally charged by it. Money impacts on how others perceive us, as well as how we perceive ourselves. In many instances, our self-worth is dependent on how much money we have or how we manage our money. Personal financial attitudes, behaviours, beliefs and anxieties are passed down from generation to generation and herein lies the possible solution to this problem. Financial openness in the family context could prepare children for the real world, while at the same time foster trust. Parents, however, should be very careful about the specific information provided to children, as well as the financial messages (sometimes non-verbal) that children receive. Parents need to ensure that children grow up to have healthy financial attitudes and beliefs to become financially healthy adults that would instil the same values in their children. This can only be done by trying to rectify the mistakes, negative messages and anxieties of the past and develop a culture where money has its rightful place in our lives, but that we can be open about it and not be as socially, culturally and psychologically dependent on it.

The contribution of this article is that it discussed money as a taboo subject, but also brings it into the realm of the family in order to indicate the importance of financial communication as it affects financial attitudes and behaviours later in life. Because money plays such an important part in everyday life, this aspect of well-being should not be neglected as it has been in the past. Parents should be educated on communication with children about financial issues, the do's and don'ts, as well as creating awareness about their own attitudes, beliefs and anxieties that should be addressed to become more financially healthy and increase the overall communication and trust within the family. The underlying issues or feelings that money brings forth in parents need to be explored in order to foster financial well-being in the family. Specifically for future research, empirical research is necessary where interviews are held with individuals (either one-on-one or in a small group context) to probe into their feelings and anxieties about money and the manifestation of these feelings in their everyday lives.

\section{References}

Abdullah, A. (2013). Examining the Value of Money in England over the Long Term (1259 - 2009), International Journal of Economics and Finance 5(3), 73-89.

Allen, K., \& Burridge, K. (2006). Forbidden Words: Taboo and the Censoring of Languages. Cambridge: Cambridge University Press.

Appadurai, A. (1986). Introduction: Commodities and the politics of value. In A. Appadurai (Ed.), The social life of things: Commodities in cultural perspective (pp. 3-63). Cambridge: Cambridge University Press.

Atwood, J.D. (2012). Couples and Money: The Last Taboo. The American Journal of Family Therapy, 40(1), 1-19.

Barth, F.D. (2001). Money as a tool in negotiating separateness and connectedness in the therapeutic relationship. Clinical Social Work Journal, 29(1), 79-93.

Belk, R.W., \& Wallendorf, M. (1990). The sacred meanings of money. Journal of Economic Psychology, 11, 35-67.

Betti, G., Dourmashkin, N., Rossi, M., \& Yin, Y.P. (2007). Consumer over-indebtedness in the EU: measurement and characteristics. Journal of Economic Studies, 34(2), 136-156.

Blaszczynski, A., \& Nower, L. (2010). Instrumental tool or drug: Relationship between attitudes to money and problem gambling. Addiction Research and Theory, 18(6), 681-691.

Burgoyne, C. (1990). Money in marriage: how patterns of allocation both reflect and conceal power. The Sociological Review, 38, 634- 
665.

Chaplin, L.N., \& John, D.R. (2010). Interpersonal influences on adolescent materialism: A new look at the role of parents and peers. Journal of Consumer Psychology, 20, $176-184$.

Dyer, A.W. (1989). Making Semiotic Sense of Money as a Medium of Exchange. Journal of Economic Issues, 23(2), 503-510.

Furnham, A., \& Argyle, M. (1998). The Psychology of Money. New York: Routledge.

Georgarakos, D., Halassos, M., \& Pasini, G, (2012), Household Debt and Social Interactions. Netspar Discussion Papers. [Online] Available: http://ssrn.com/abstract=2181948 (June 14, 2013)

Goodwin, R. (2008). Social Support and the Wealthy Porcupine: Pain, Social Support, Money, and Culture. Psychological Inquiry, 19, $179-185$.

Herbert, C. (2002). Filthy Lucre: Victorian Ideas of Money. Victorian Studies, 44(2), 185-213.

Jorgensen, B.L., \& Savla, J. (2012). Financial Literacy of Young Adults: The Importance of parental Socialization. Family Relations, 59, 465-478.

Klontz, B.T., Bivens, A., Klontz, P.T., Wada, J., \& Kahler, R. (2008). The Treatment of Disordered Money Behaviors: Results of an Open Clinical Trial. Psychological Services, 5(3), 295-308.

Lea, S.E.G., \& Webley, P. (2006). Money as tool, money as drug: The biological psychology of a strong incentive. Behavioral and Brain Sciences, 29, 161-209.

Lowrance, J, (2011), Dismantling the Money Taboo: Mental Health Professionals' Call to Action. White Paper. [Online] Available: http://www.financialpsychologyceus.com/Money-Taboo-White-Paper.pdf (September 15, 2012)

Matthews, A. (1991). If I Think about Money so much, Why Can't I Figure it out. New York: Summit Books.

McKinnon, R.I. (2001). The problem of dollar encroachment in emerging markets. Journal of Policy Modelling, 23(3), 301-319.

Mitchell, T.R., \& Mickel, A.E. (1999). The meaning of money: an individual-difference perspective. Academy of Management Review, 24(3), 568-578.

Moschis, G,P. (1985). The Role of Family Communication in Consumer Socialization of Children and Adolescents. Journal of Consumer research, 11(4), 898-913.

Ng'ang'a, M.J., \& Nyongesa, W.J. (2012). The Impact of Organisational Culture on Performance of Educational Institutions. International Journal of Business and Social Science, 3(8), 211-217.

Oxford English Dictionary, (2013). [Online] Available: http://oxforddictionaries.com/definition/english/taboo (July 24, 2013)

Petronio, S. (2002). Boundaries of privacy: Dialectics of disclosure. New York: State University of New York Press.

Rynes, S.L., Gerhart, B., \& Minette, K.A. (2004). The importance of pay in employee motivation: discrepancies between what people say and what they do. Human Resource Management, 43(4), 381-394.

Romo, K.L. (2011). Money Talks: Revealing and Concealing Financial Information in Families. Journal of Family Education, 11(4), 264281.

Sardoni, C. (2008). Some Notes on the Nature of Money and the Future of Monetary Policy. Review of Social Economy, 66(4), 523-537.

Shulman, L. (2008). Learning to Talk about Taboo Subjects: A Lifelong Professional Challenge. Social Works with Groups, 25(1-2), 139150.

Shepherd, H.R., \& Stephens, N.M. (2010). Using Culture to Explain Behaviour: An Integrative Cultural Approach. Social Psychology Quarterly, 73(4), 353-357.

Simmel, G. (2004). The Philosophy of Money. (3rd enlarged ed.). Routledge: New York

Trachtman, R. (1999). The money taboo: its effects in everyday life and in the practice of psychotherapy. Clinical Social Work Journal, $27(3), 275-288$.

Vogler, C. (2005). Cohabitating couples: Rethinking money in the household at the beginning of the twenty first century. The Sociological Review, 53(1), 1-29.

Wang, C-C., Cheng, Y-Y., Chiou, W-B., \& Kung, C-C. (2012). Shame for money: Shame enhances the incentive value of economic resources. Judgement and Decision Making, 7(1), 77-85.

Weisgram, E.S., Bigler, R.S., \& Liben, L.S. (2010). Gender, Values, and Occupational Interests Among Children, Adolescents and Adults. Child Development, 81(3), 778-796.

Zhang, L. (2009). An Exchange Theory of Money and Self-Esteem in Decision Making. Review of General Psychology, 13(1), 66-76.

Zhou, X., Vohs, K.D., \& Baumeister, R.F. (2009). The Symbolic Power of Money: Reminders of Money Alter Social Distress and Physical Pain. Psychological Science, 20(6), 700-706. 